\title{
Oscillation Criteria for a Class of Second-Order Nonlinear Differential Equations with Damping Term
}

\author{
Zigen Ouyang, ${ }^{1,2}$ Jichao Zhong, ${ }^{1,2}$ and Shuliang Zou ${ }^{1}$ \\ ${ }^{1}$ Center of Nuclear Energy Economy and Management, University of South China, \\ Hengyang 421001, China \\ ${ }^{2}$ School of Mathematics and Physics, University of South China, Hengyang 421001, China \\ Correspondence should be addressed to Zigen Ouyang, zigenouyang@yahoo.com.cn
}

Received 31 August 2009; Accepted 29 September 2009

Recommended by Yong Zhou

A class of second-order nonlinear differential equations with damping term $\left(r(t)\left|x^{\prime}(t)\right|^{\sigma-1} x^{\prime}(t)\right)^{\prime}+$ $p(t)\left|x^{\prime}(t)\right|^{\sigma-1} x^{\prime}(t)+q(t) f(x(t))=0$ are investigated in this paper. By using a new method, we obtain some new sufficient conditions for the oscillation of the above equation, and some references are extended in this paper. Examples are inserted to illustrate this result.

Copyright (C) 2009 Zigen Ouyang et al. This is an open access article distributed under the Creative Commons Attribution License, which permits unrestricted use, distribution, and reproduction in any medium, provided the original work is properly cited.

\section{Introduction}

Consider the following second-order nonlinear differential equations with damping term:

$$
\left(r(t)\left|x^{\prime}(t)\right|^{\sigma-1} x^{\prime}(t)\right)^{\prime}+p(t)\left|x^{\prime}(t)\right|^{\sigma-1} x^{\prime}(t)+q(t) f(x(t))=0, \quad t \geq t_{0}
$$

where $r(t) \in C^{1}\left(\left[t_{0}, \infty\right) ; R^{+}\right), p(t), q(t) \in C\left(\left[t_{0}, \infty\right) ; R\right), \sigma$ is a positive constant, and $f$ is a continuous real-valued function on the real line $R$ and satisfies $x f(x) \geq 0$ for $x \neq 0$. We restrict our attention to those solutions $x(t)$ of (1.1) which exist on some half line $\left[t_{x}, \infty\right)$ and satisfy $\sup \{|x(t)|: t \geq T\}>0$ for any $T \geq t_{x}$.

Recently, there are many authors who have investigated the oscillation for secondorder differential equations [1-9], Li [10] and Zhao investigated oscillation criteria for the following equation:

$$
\left(r(t)\left(x^{\prime}(t)\right)^{\sigma}\right)^{\prime}+p(t)\left(x^{\prime}(t)\right)^{\sigma}+q(t) f(x(t))=0, \quad t \geq t_{0}
$$


where $\sigma$ is a quotient of odd positive integer. It is obvious that (1.2) is a special case of (1.1). In fact, the conditions of Theorem 3.2 in [10] are too complex. following:

More recently, Rogovchenko and Tuncay [11] have obtained oscillation criteria of the

$$
\left(r(t) x^{\prime}(t)\right)^{\prime}+p(t) x^{\prime}(t)+q(t) f(x(t))=0, \quad t \geq t_{0}
$$

Motivated by the above discussions, we investigate the oscillation of (1.1) in this paper; our oscillatory conditions and the proof of the main results are more simple than those of Theorem 3.2 in [10].

A solution $x(t)$ of (1.1) is oscillatory if and only if it has arbitrarily large zeros; otherwise, it is nonoscillatory. Equation (1.1) is oscillatory if and only if every solution of (1.1) is oscillatory.

The paper is arranged as follows. In Section 2, we will establish our main results. Finally, examples are given to illustrate our results.

\section{Main Results}

To obtain our results, we introduce a lemma as follows.

Lemma 2.1 (see [2,3]). Let the function $K(t, s, x): R \times R \times R^{+} \rightarrow R$ be such that for each fixed $t$, $s$, the function $K(t, s, \cdot)$ is nondecreasing. Further, let $h(t)$ be a given function and $u(t)$ satisfies that

$$
u(t) \geq(\leq) h(t)+\int_{t_{0}}^{t} K(t, s, u(s)) d s, \quad t \geq t_{0}
$$

and $v^{*}(t)$ is the minimal (maximal) solution of

$$
v(t)=h(t)+\int_{t_{0}}^{t} K(t, s, v(s)) d s, \quad t \geq t_{0} .
$$

Then $u(t) \geq(\leq) v^{*}(t)$ for all $t \geq t_{0}$.

Now, we give our main results.

Theorem 2.2. Assume that $f^{\prime}(x) \geq 0, p(t) \leq 0, q(t)>0$, and $\int_{t_{0}}^{\infty}\left(1 / r^{1 / \sigma}(t)\right) d t=\infty$ hold. Suppose that there exists a positive function $\rho(t)$ such that

$$
\begin{aligned}
& \int_{t_{0}}^{\infty} q(t) \rho(t) d t=\infty, \\
& p(t) \rho(t) \geq r(t) \rho^{\prime}(t) .
\end{aligned}
$$

Then every solution of (1.1) is oscillatory. 
Proof. Assume that (1.1) has a nonoscillatory solution $x(t)$. Without loss of generality, suppose that it is an eventually positive solution (if it is an eventually negative solution, the proof is similar), that is, $x(t)>0$ for all $t \geq t_{0}$.

We consider the following three cases.

Case 1. Suppose that $x^{\prime}(t)$ is oscillatory. Then there exists $t_{1} \geq t_{0}$ such that $x^{\prime}\left(t_{1}\right)=0$. From (1.1), we have

$$
\begin{aligned}
& \left(r(t)\left|x^{\prime}(t)\right|^{\sigma-1} x^{\prime}(t) \exp \left(\int_{t_{0}}^{t} \frac{p(s)}{r(s)} d s\right)\right)^{\prime} \\
& \quad=\left(r(t)\left|x^{\prime}(t)\right|^{\sigma-1} x^{\prime}(t)\right)^{\prime} \exp \left(\int_{t_{0}}^{t} \frac{p(s)}{r(s)} d s\right)+p(t)\left|x^{\prime}(t)\right|^{\sigma-1} x^{\prime}(t) \exp \left(\int_{t_{0}}^{t} \frac{p(s)}{r(s)} d s\right) \\
& =-q(t) f(x(t)) \exp \left(\int_{t_{0}}^{t} \frac{p(s)}{r(s)} d s\right)<0,
\end{aligned}
$$

which means that

$$
\begin{aligned}
& r(t)\left|x^{\prime}(t)\right|^{\sigma-1} x^{\prime}(t) \exp \left(\int_{t_{0}}^{t} \frac{p(s)}{r(s)} d s\right) \\
& <r\left(t_{1}\right)\left|x^{\prime}\left(t_{1}\right)\right|^{\sigma-1} x^{\prime}\left(t_{1}\right) \exp \left(\int_{t_{0}}^{t_{1}} \frac{p(s)}{r(s)} d s\right)=0, \quad t>t_{1},
\end{aligned}
$$

it follows that $x^{\prime}(t)<0$ for all $t>t_{1}$, which contradicts to the assumption that $x^{\prime}(t)$ is oscillatory.

Case 2. Suppose that $x^{\prime}(t)<0$. From (1.1), we obtain

$$
-\left(r(t)\left|x^{\prime}(t)\right|^{\sigma-1} x^{\prime}(t)\right)^{\prime}=\left(r(t)\left(-x^{\prime}(t)\right)^{\sigma}\right)^{\prime}=-p(t)\left(-x^{\prime}(t)\right)^{\sigma}+q(t) f(x(t)) \geq 0,
$$

then there exists an $M>0$ and a $t_{1} \geq t_{0}$, such that

$$
r(t)\left(-x^{\prime}(t)\right)^{\sigma} \geq M, \quad t \geq t_{1}
$$

it follows

$$
x(t) \leq-\int_{t_{1}}^{\infty} \frac{1}{r^{1 / \sigma}(t)} M^{1 / \sigma} d t+x\left(t_{1}\right), \quad t \geq t_{1}
$$

which means that $\lim _{t \rightarrow \infty} x(t)=-\infty$, this contradicts the assumption that $x(t)>0$. 
Case 3. Suppose that $x^{\prime}(t)>0$. Let $w(t)=\rho(t) r(t)\left(x^{\prime}(t)\right)^{\sigma}$, then

$$
w^{\prime}(t)=\left(r(t)\left(x^{\prime}(t)\right)^{\sigma}\right)^{\prime} \rho(t)+r(t)\left(x^{\prime}(t)\right)^{\sigma} \rho^{\prime}(t), \quad t \geq t_{0}
$$

in view of (1.1), we obtain

$$
\frac{w^{\prime}(t)}{f(x(t))}=-q(t) \rho(t)-\frac{\rho(t) p(t)\left(x^{\prime}(t)\right)^{\sigma}}{f(x(t))}+\frac{\rho^{\prime}(t) r(t)\left(x^{\prime}(t)\right)^{\sigma}}{f(x(t))}, \quad t \geq t_{0}
$$

noticing that

$$
\begin{aligned}
\left(\frac{w(t)}{f(x(t))}\right)^{\prime} & =\frac{w^{\prime}(t) f(x(t))-w(t) f^{\prime}(x(t)) x^{\prime}(t)}{f^{2}(x(t))} \\
& =-q(t) \rho(t)-\frac{\rho(t) p(t)\left(x^{\prime}(t)\right)^{\sigma}}{f(x(t))}+\frac{\rho^{\prime}(t) r(t)\left(x^{\prime}(t)\right)^{\sigma}}{f(x(t))}-\frac{w(t) f^{\prime}(x(t)) x^{\prime}(t)}{f^{2}(x(t))}, \quad t \geq t_{0},
\end{aligned}
$$

integrating the above from $t_{0}$ to $t$, we get

$$
\frac{w(t)}{f(x(t))}=\frac{w\left(t_{0}\right)}{f\left(x\left(t_{0}\right)\right)}-\int_{t_{0}}^{t}\left(q(s) \rho(s)+\frac{\left(\rho(s) p(s)-\rho^{\prime}(s) r(s)\right)\left(x^{\prime}(s)\right)^{\sigma}}{f(x(s))}+\frac{w(s) x^{\prime}(s) f^{\prime}(x(s))}{f^{2}(x(s))}\right) d s
$$

Using (2.3), (2.4), and $x^{\prime}(t)>0$, we have

$$
0 \leq \lim _{t \rightarrow \infty} \frac{w(t)}{f(x(t))}=-\infty
$$

this is a contradiction, the proof is complete.

Remark 2.3. If we replace $p(t) \leq 0, q(t)>0$ by $p(t) \leq 0, q(t) \leq 0, \lim _{t \rightarrow \infty}(p(t) / q(t))=M>0$, Theorem 2.2 holds also.

Theorem 2.4. Assume that $f^{\prime}(x) \geq 0$ holds. Suppose also that

$$
\begin{gathered}
\rho_{0}(t)=\exp \left(\int_{t_{0}}^{t} \frac{p(s)}{r(s)} d s\right), \\
\int_{t_{0}}^{\infty} \frac{d t}{\left(\rho_{0}(t) r(t)\right)^{1 / \sigma}}=\infty,
\end{gathered}
$$

and $\rho_{0}(t)$ such that (2.3) holds. Then every solution of (1.1) is oscillatory. 
Proof. To the contrary, (1.1) has a nonoscillatory solution $x(t)$. Without loss of generality, we assume that $x(t)$ is an eventually positive solution. Let $w(t)=\rho_{0}(t) r(t)\left|x^{\prime}(t)\right|^{\sigma-1} x^{\prime}(t)$, then $w(t) x^{\prime}(t)=\rho_{0}(t) r(t)\left|x^{\prime}(t)\right|^{\sigma-1}\left(x^{\prime}(t)\right)^{2} \geq 0$ for $t \geq t_{0}$ and

$$
w^{\prime}(t)=\left(r(t)\left|x^{\prime}(t)\right|^{\sigma-1} x^{\prime}(t)\right)^{\prime} \rho_{0}(t)+r(t)\left|x^{\prime}(t)\right|^{\sigma-1} x^{\prime}(t) \rho_{0}^{\prime}(t), \quad t \geq t_{0},
$$

in view of (1.1) and (2.15), we obtain

$$
\frac{w^{\prime}(t)}{f(x(t))}=-q(t) \rho_{0}(t), \quad t \geq t_{0}
$$

since

$$
\left(\frac{w(t)}{f(x(t))}\right)^{\prime}=\frac{w^{\prime}(t) f(x(t))-w(t) f^{\prime}(x(t)) x^{\prime}(t)}{f^{2}(x(t))}=-q(t) \rho_{0}(t)-\frac{w(t) f^{\prime}(x(t)) x^{\prime}(t)}{f^{2}(x(t))}, \quad t \geq t_{0}
$$

integrating the above from $t_{0}$ to $t$, we have

$$
-\frac{w(t)}{f(x(t))}=-\frac{w\left(t_{0}\right)}{f\left(x\left(t_{0}\right)\right)}+\int_{t_{0}}^{t} q(s) \rho_{0}(s) d s+\int_{t_{0}}^{t} \frac{w(s) x^{\prime}(s) f^{\prime}(x(s))}{f^{2}(x(s))} d s, \quad t \geq t_{0}
$$

In view of (2.3), there exists a constant $m>0$ and $t_{1} \geq t_{0}$ such that

$$
-\frac{w\left(t_{0}\right)}{f\left(x\left(t_{0}\right)\right)}+\int_{t_{0}}^{t} q(s) \rho_{0}(s) d s+\int_{t_{0}}^{t_{1}} \frac{w(s) x^{\prime}(s) f^{\prime}(x(s))}{f^{2}(x(s))} d s \geq m,
$$

which means that

$$
-\frac{w(t)}{f(x(t))} \geq m+\int_{t_{1}}^{t} \frac{w(s) x^{\prime}(s) f^{\prime}(x(s))}{f^{2}(x(s))} d s
$$

Because that $x(t)$ is positive, then (2.22) implies $-w(t)>0$, or equivalently $x^{\prime}(t)<0$. Let

$$
u(t)=-w(t)=-\rho_{0}(t) r(t)\left|x^{\prime}(t)\right|^{\sigma-1} x^{\prime}(t)=\rho_{0}(t) r(t)\left(-x^{\prime}(t)\right)^{\sigma},
$$

thus (2.22) can be changed as

$$
u(t) \geq m f(x(t))+\int_{t_{1}}^{t} \frac{f(x(t)) f^{\prime}(x(s))\left(-x^{\prime}(s)\right)}{f^{2}(x(s))} u(s) d s .
$$

Define

$$
K(t, s, u)=\frac{f(x(t)) f^{\prime}(x(s))\left(-x^{\prime}(s)\right)}{f^{2}(x(s))} u
$$


Then, for any fixed $t$ and $s, K(t, s, u)$ is nondecreasing in $u$. Let $v(t)$ be the minimal solution of the equation

$$
v(t)=m f(x(t))+\int_{t_{1}}^{t} \frac{f(x(t)) f^{\prime}(x(s))\left(-x^{\prime}(s)\right)}{f^{2}(x(s))} v(s) d s .
$$

Applying Lemma 2.1, we obtain

$$
u(t) \geq v(t), \quad t \geq t_{0}
$$

Dividing both sides of (2.26) by $f(x(t))$ and deriving both sides of (2.26), it follows

$$
\left(\frac{v(t)}{f(x(t))}\right)^{\prime}=\left(m+\int_{t_{1}}^{t} \frac{f^{\prime}(x(s))\left(-x^{\prime}(s)\right)}{f^{2}(x(s))} v(s) d s\right)^{\prime}=\frac{f^{\prime}(x(t))\left(-x^{\prime}(t)\right)}{f^{2}(x(t))} v(t)
$$

On the other hand,

$$
\left(\frac{v(t)}{f(x(t))}\right)^{\prime}=\frac{v^{\prime}(t)}{f(x(t))}-\frac{f^{\prime}(x(t)) x^{\prime}(t)}{f^{2}(x(t))} v(t)
$$

Combining (2.28) and (2.29), it means

$$
v^{\prime}(t) \equiv 0
$$

So $v(t)=v\left(t_{1}\right)=m f\left(x\left(t_{1}\right)\right), t \geq t_{0}$. From (2.27), we obtain

$$
-x^{\prime}(t) \geq\left(m f\left(x\left(t_{1}\right)\right)\right)^{1 / \sigma} \frac{1}{\left(\rho_{0}(t) r(t)\right)^{1 / \sigma}}, \quad t \geq t_{1} .
$$

Integrating both sides of the above from $t_{1}$ to $t$, we have

$$
-x(t)+x\left(t_{1}\right) \geq\left(m f\left(x\left(t_{1}\right)\right)\right)^{1 / \sigma} \int_{t_{1}}^{t} \frac{d s}{\left(\rho_{0}(s) r(s)\right)^{1 / \sigma}} .
$$

Letting $t \rightarrow \infty$ in (2.32), and using (2.16), it follows that $\lim _{t \rightarrow \infty} x(t) \leq-\infty$, which contradicts to that $x(t)$ is eventually positive. The proof is complete.

In the following, we always suppose that $H(t) \in C^{2}(R ; R)$ and it satisfies the following two conditions:

$\left(H_{1}\right) H(t)>0$ for $t \geq t_{0}, H(t)$ is a bounded function;

$\left(H_{2}\right) H^{\prime}(t)=h(t), h(t)$ is a bounded function. 
Theorem 2.5. Assume that $f^{\prime}(x) \geq 0, \int_{t_{0}}^{\infty}\left(1 / r^{1 / \sigma}(t)\right) d t=\infty$ hold, and

$$
p(t) \leq 0, \quad q(t)>0,
$$

or

$$
p(t) \leq 0, \quad q(t) \leq 0, \quad \lim _{t \rightarrow \infty} \frac{p(t)}{q(t)}=M>0
$$

Suppose further that there exists a function $H(t)$ that satisfies $\left(H_{1}\right),\left(H_{2}\right)$, and such that

$$
\begin{gathered}
\int_{t_{0}}^{\infty} H(t) \varphi(t) d t=\infty, \\
\limsup _{t \rightarrow \infty} v(t) r(t)<\infty,
\end{gathered}
$$

where

$$
\begin{gathered}
\varphi(t)=v(t)\left(q(t)-p(t) h(t)-(r(t) h(t))^{\prime}\right), \\
v(t)=\exp \left(\int_{t_{0}}^{t}\left(\frac{p(s)}{r(s)}-\frac{h(s)}{H(s)}\right) d s\right) .
\end{gathered}
$$

Then every solution of (1.1) is oscillatory.

Proof. For the sake of contradiction, (1.1) has a nonoscillatory solution $x(t)$. Without loss of generality, we may assume that $x(t)>0$ for all $t \geq t_{0}$.

Define

$$
u(t)=v(t) r(t)\left(\frac{\left|x^{\prime}(t)\right|^{\sigma-1} x^{\prime}(t)}{f(x(t))}+h(t)\right)
$$

Deriving (2.39), we get

$$
\begin{aligned}
u^{\prime}(t)= & \left(\frac{p(t)}{r(t)}-\frac{h(t)}{H(t)}\right) u(t) \\
& +v(t)\left[-\frac{p(t)\left|x^{\prime}(t)\right|^{\sigma-1} x^{\prime}(t)}{f(x(t))}-q(t)-\frac{r(t)\left|x^{\prime}(t)\right|^{\sigma-1}\left(x^{\prime}(t)\right)^{2} f^{\prime}(x(t))}{f^{2}(x(t))}+(r(t) h(t))^{\prime}\right] \\
\leq & -\frac{h(t)}{H(t)} u(t)+p(t) v(t) h(t)-v(t) q(t)+v(t)(r(t) h(t))^{\prime} \\
= & -\frac{h(t)}{H(t)} u(t)-\varphi(t) .
\end{aligned}
$$


Multiplying (2.40) by $H(t)$, it follows

$$
\varphi(t) H(t) \leq-H(t) u^{\prime}(t)-h(t) u(t)
$$

We consider the following three cases.

Case 1 ( $u(t)$ is oscillatory). Then there exists a sequence $\left\{t_{n}\right\}, n=1,2, \ldots, t_{n} \rightarrow \infty$ as $n \rightarrow \infty$ and such that $u\left(t_{n}\right)=0, n=1,2, \ldots$ Integrating both sides of (2.41) from $t_{0}$ to $t_{n}$, we obtain

$$
\begin{aligned}
\int_{t_{0}}^{t_{n}} H(t) \varphi(t) d t & \leq-\int_{t_{0}}^{t_{n}} H(t) u^{\prime}(t) d t-\int_{t_{0}}^{t_{n}} h(t) u(t) d t \\
& =-\left.H(t) u(t)\right|_{t_{0}} ^{t_{n}}-\int_{t_{0}}^{t_{n}}\left(-H^{\prime}(t) u(t)+h(t) u(t)\right) d t \\
& =H\left(t_{0}\right) u\left(t_{0}\right)-H\left(t_{n}\right) u\left(t_{n}\right)=H\left(t_{0}\right) u\left(t_{0}\right),
\end{aligned}
$$

that is

$$
\lim _{t_{n} \rightarrow \infty} \int_{t_{0}}^{t_{n}} H(t) \varphi(t) d t \leq H\left(t_{0}\right) u\left(t_{0}\right)
$$

which contradicts (2.35).

Case $2\left(u(t)\right.$ is eventually positive). Integrating both sides of (2.41) from $t_{0}$ to $\infty$, we obtain

$$
\int_{t_{0}}^{\infty} H(t) \varphi(t) d t \leq H\left(t_{0}\right) u\left(t_{0}\right)-\lim _{t \rightarrow \infty} H(t) u(t) \leq H\left(t_{0}\right) u\left(t_{0}\right),
$$

which also contradicts to (2.35).

Case $3\left(u(t)\right.$ is eventually negative). If $\lim _{\sup _{t \rightarrow \infty}} u(t)>-\infty$, then there exists a sequence $\left\{\bar{t}_{n}\right\}, n=1,2, \ldots$, that satisfies $\left\{\bar{t}_{n}\right\} \rightarrow \infty$ as $n \rightarrow \infty$ and such that $\lim _{\bar{t}_{n \rightarrow \infty}} u\left(\bar{t}_{n}\right)=$ $\limsup _{t \rightarrow \infty} u(t)=M_{1}>-\infty$. Because $H(t)$ is a bounded function, then there exists a $M_{2}>0$ such that $H\left(\bar{t}_{n}\right) \leq M_{2}, n=1,2, \ldots$ According to (2.41), we obtain

$$
\int_{t_{0}}^{\bar{t}_{n}} H(t) \varphi(t) d t \leq H\left(t_{0}\right) u\left(t_{0}\right)-H\left(\bar{t}_{n}\right) u\left(\bar{t}_{n}\right) \leq H\left(t_{0}\right) u\left(t_{0}\right)-M_{2} u\left(\bar{t}_{n}\right) .
$$

Using (2.35) and taking limit as $\bar{t}_{n} \rightarrow \infty$, it is easy to show that

$$
\begin{aligned}
\infty & =\lim _{\bar{t}_{n} \rightarrow \infty} \int_{t_{0}}^{\bar{t}_{n}} H(t) \varphi(t) d t \leq H\left(t_{0}\right) u\left(t_{0}\right)-\lim _{\bar{t}_{n} \rightarrow \infty} H\left(\bar{t}_{n}\right) u\left(\bar{t}_{n}\right) \\
& \leq H\left(t_{0}\right) u\left(t_{0}\right)-M_{1} M_{2}<\infty,
\end{aligned}
$$

which is obviously a contradiction. 
If $\lim \sup _{t \rightarrow \infty} u(t)=-\infty, \lim _{t \rightarrow \infty} u(t)=-\infty$. From the definition of $h(t)$, combining (2.36) and (2.39), it follows that $x^{\prime}(t)<0$ and $\lim _{t \rightarrow \infty}\left(\left|x^{\prime}(t)\right|^{\sigma-1} x^{\prime}(t) / f(x(t))\right)=-\infty$, which means that $\lim _{t \rightarrow \infty}\left(\left(-x^{\prime}(t)\right)^{\sigma} / f(x(t))\right)=\infty$. Owing to $p(t) \leq 0, q(t) \geq 0$, or $p(t) \leq 0$, $q(t) \leq 0$ and $\lim _{t \rightarrow \infty}(p(t) / q(t))=M>0$, using the similar method of the proof of Case 2 in Theorem 2.2, we will derive a contradiction. Then the proof is complete.

Theorem 2.6. Assume that (2.36) holds, $f^{\prime}(x) \geq 0, \int_{t_{0}}^{\infty}\left(1 / r^{1 / \sigma}(t)\right) d t=\infty$, and

$$
p(t) \leq 0, \quad q(t)>0,
$$

or

$$
p(t) \leq 0, \quad q(t) \leq 0, \quad \lim _{t \rightarrow \infty} \frac{p(t)}{q(t)}=M>0
$$

Suppose further that there exists a function $H(t)$ that satisfies $\left(H_{1}\right),\left(H_{2}\right)$ and such that

$$
\int_{t_{0}}^{\infty} H(t) \bar{\varphi}(t) d t=\infty
$$

where

$$
\bar{\varphi}(t)=v(t)\left(q(t)+p(t) h(t)+(r(t) h(t))^{\prime}\right),
$$

and $v(t)$ is defined in (2.38). Then every solution of (1.1) is oscillatory.

Proof. For the sake of contradiction, (1.1) has a nonoscillatory solution. Without loss of generality, we may assume that (1.1) has an eventually positive solution (if it has an eventually negative solution, the proof is similar), then there exists a $t_{1}>t_{0}$ such that $x(t)>0$ for all $t \geq t_{1}$. Define

$$
u(t)=v(t) r(t)\left(\frac{\left|x^{\prime}(t)\right|^{\sigma-1} x^{\prime}(t)}{f(x(t))}-h(t)\right)
$$

The rest of the proof is similar to Theorem 2.5. The proof is complete.

Theorem 2.7. Assume that (2.36) holds, $f^{\prime}(x) \geq 0, \int_{t_{0}}^{\infty}\left(1 / r^{1 / \sigma}(t)\right) d t=\infty$, and

$$
p(t) \leq 0, \quad q(t)>0,
$$

or

$$
p(t) \leq 0, \quad q(t) \leq 0, \quad \lim _{t \rightarrow \infty} \frac{p(t)}{q(t)}=M>0 .
$$


Suppose further that there exists a function $H(t)$ that satisfies $\left(H_{1}\right),\left(H_{2}\right)$ and such that

$$
\int_{t_{0}}^{\infty} H(t) \phi(t) d t=\infty
$$

where

$$
\phi(t)=v(t)\left(-p(t) h(t)-(r(t) h(t))^{\prime}\right),
$$

where $v(t)$ is defined in (2.38). Then every solution of (1.1) is oscillatory.

Proof. For the sake of contradiction, (1.1) has a nonoscillatory solution $x(t)$. Without loss of generality, we may assume that $x(t)>0$ for all $t \geq t_{0}$.

Define

$$
u(t)=v(t) r(t)\left(\frac{\left|x^{\prime}(t)\right|^{\sigma-1} x^{\prime}(t)}{x(t)}+h(t)\right)
$$

Noting that $x f(x) \geq 0$ for $x \neq 0$, so $f(x) / x \geq 0$ for $x \neq 0$. Deriving (2.56), we obtain

$$
\begin{aligned}
u^{\prime}(t)= & \left(\frac{p(t)}{r(t)}-\frac{h(t)}{H(t)}\right) u(t) \\
& +v(t)\left[-\frac{p(t)\left|x^{\prime}(t)\right|^{\sigma-1} x^{\prime}(t)}{x(t)}-\frac{q(t) f(x(t))}{x(t)}-\frac{r(t)\left|x^{\prime}(t)\right|^{\sigma-1}\left(x^{\prime}(t)\right)^{2}}{x^{2}(t)}+(r(t) h(t))^{\prime}\right] \\
\leq & -\frac{h(t)}{H(t)} u(t)+p(t) v(t) h(t)+v(t)(r(t) h(t))^{\prime} \\
= & -\frac{h(t)}{H(t)} u(t)-\phi(t) .
\end{aligned}
$$

Multiplying (2.57) by $H(t)$, we get

$$
H(t) \phi(t) \leq-H(t) u^{\prime}(t)-h(t) u(t) .
$$

The rest of the proof is similar to Theorem 2.5; the proof is complete.

Theorem 2.8. Assume that (2.36) holds, $f^{\prime}(x) \geq 0, \int_{t_{0}}^{\infty}\left(1 / r^{1 / \sigma}(t)\right) d t=\infty$, and

$$
p(t) \leq 0, \quad q(t)>0,
$$

or

$$
p(t) \leq 0, \quad q(t) \leq 0, \quad \lim _{t \rightarrow \infty} \frac{p(t)}{q(t)}=M>0 .
$$


Suppose further that there exists a function $H(t)$ satisfies $\left(H_{1}\right),\left(H_{2}\right)$ and such that

$$
\int_{t_{0}}^{\infty} H(t) \bar{\phi}(t) d t=\infty
$$

where

$$
\bar{\phi}(t)=v(t)\left(p(t) h(t)+(r(t) h(t))^{\prime}\right)
$$

where $v(t)$ is defined in (2.38). Then every solution of (1.1) is oscillatory.

Proof. For the sake of contradiction, (1.1) has a nonoscillatory solution $x(t)$. Without loss of generality, we may assume that $x(t)>0$ for all $t \geq t_{0}$.

Define

$$
u(t)=v(t) r(t)\left(\frac{\left|x^{\prime}(t)\right|^{\sigma-1} x^{\prime}(t)}{x(t)}-h(t)\right)
$$

The rest of the proof is similar to Theorem 2.5; the proof is complete.

\section{Examples}

Example 3.1. Consider the following delay differential equation:

$$
\left(t x^{\prime}(t)\right)^{\prime}-2 x^{\prime}(t)+\left(t+\frac{3}{4 t}\right) x(t)=0 .
$$

It is obvious that $\sigma=1, q(t)=(t+3 / 4 t)>0, p(t)=-2<0, r(t)=t$, and $\int_{t_{0}}^{\infty}(1 / t) d t=\infty$. It is difficult to distinguish whether every solution of (3.1) is oscillatory by Theorem 3.2 of [10].

By taking $\rho(t)=1 / t^{2}$, then

$$
\begin{gathered}
\int_{t_{0}}^{\infty} q(t) \rho(t) d t=\int_{t_{0}}^{\infty}\left(t+\frac{3}{4 t}\right) \frac{1}{t^{2}} d t=\infty, \\
p(t) \rho(t)=-\frac{2}{t^{2}}=r(t) \rho^{\prime}(t) .
\end{gathered}
$$

From Theorem 2.2 or Theorem 2.4, it is easy to show that (3.1) is oscillatory.

In fact, $x(t)=t^{1 / 2} \cos t$ is such an oscillatory solution.

Example 3.2. Consider the following differential equation:

$$
\left(t x^{\prime}(t)\right)^{\prime}-x^{\prime}(t)+t x(t)=0
$$

It is obvious that $\sigma=1, r(t)=t, p(t)=-1<0, q(t)=t>0$, and $\int_{t_{0}}^{\infty}(1 / r(t)) d t=\int_{t_{0}}^{\infty}(1 / t) d t=\infty$. 
We are taking $H(t)=C>0, h(t)=0$. By a simple calculation, it is easy to show that $v(t)=\exp \left(\int_{t_{0}}^{t}(p(s) / r(s)-h(s) / H(s)) d s\right)=\exp \left(\int_{t_{0}}^{t}(-1 / s-0 / C) d s\right)=t_{0} / t$, $\limsup _{t \rightarrow \infty} v(t) r(t)=\limsup _{t \rightarrow \infty} t_{0}<\infty, \varphi(t)=v(t)\left(q(t)-p(t) h(t)-(r(t) h(t))^{\prime}\right)=t_{0}$, and $\int_{t_{0}}^{\infty} H(t) \varphi(t) d t=\int_{t_{0}}^{\infty} t_{0} C d t=\infty$.

From Theorem 2.5 or Theorem 2.6, it follows that (3.3) is oscillatory.

In fact, $x(t)=\sin t$ is such an oscillatory solution.

\section{Acknowledgments}

This work was supported by the Natural Science Foundation of Hunan Province under Grant no. 07JJ3130, the Doctor Foundation of University of South China under Grant no. 5-XQD-2006-9, and the Subject Lead Foundation of University of South China under Grant no. 2007XQD13.

\section{References}

[1] H. J. Li, "Oscillation criteria for second order linear differential equations," Journal of Mathematical Analysis and Applications, vol. 194, no. 1, pp. 217-234, 1995.

[2] W.-T. Li, "Oscillation of certain second-order nonlinear differential equations," Journal of Mathematical Analysis and Applications, vol. 217, no. 1, pp. 1-14, 1998.

[3] P. J. Y. Wong and R. P. Agarwal, "Oscillatory behavior of solutions of certain second order nonlinear differential equations," Journal of Mathematical Analysis and Applications, vol. 198, no. 2, pp. 337-354, 1996.

[4] P. J. Y. Wong and R. P. Agarwal, "The oscillation and asymptotically monotone solutions of secondorder quasilinear differential equations," Applied Mathematics and Computation, vol. 79, no. 2-3, pp. 207-237, 1996.

[5] W. Li and J. R. Yan, "Oscillation criteria for second order superlinear differential equations," Indian Journal of Pure and Applied Mathematics, vol. 28, no. 6, pp. 735-740, 1997.

[6] A. Tiryaki and A. Zafer, "Oscillation criteria for second order nonlinear differential equations with damping," Turkish Journal of Mathematics, vol. 24, no. 2, pp. 185-196, 2000.

[7] J. S. W. Wong, "On Kamenev-type oscillation theorems for second-order differential equations with damping," Journal of Mathematical Analysis and Applications, vol. 258, no. 1, pp. 244-257, 2001.

[8] X. Yang, "Oscillation criteria for nonlinear differential equations with damping," Applied Mathematics and Computation, vol. 136, no. 2-3, pp. 549-557, 2003.

[9] O. G. Mustafa, S. P. Rogovchenko, and Yu. V. Rogovchenko, "On oscillation of nonlinear second-order differential equations with damping term," Journal of Mathematical Analysis and Applications, vol. 298, no. 2, pp. 604-620, 2004.

[10] W.-T. Li and P. Zhao, "Oscillation theorems for second-order nonlinear differential equations with damped term," Mathematical and Computer Modelling, vol. 39, no. 4-5, pp. 457-471, 2004.

[11] Yu. V. Rogovchenko and F. Tuncay, "Oscillation criteria for second-order nonlinear differential equations with damping," Nonlinear Analysis, vol. 69, no. 1, pp. 208-221, 2008. 


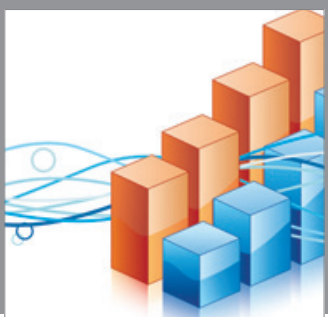

Advances in

Operations Research

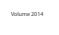

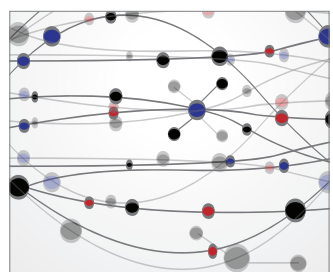

\section{The Scientific} World Journal
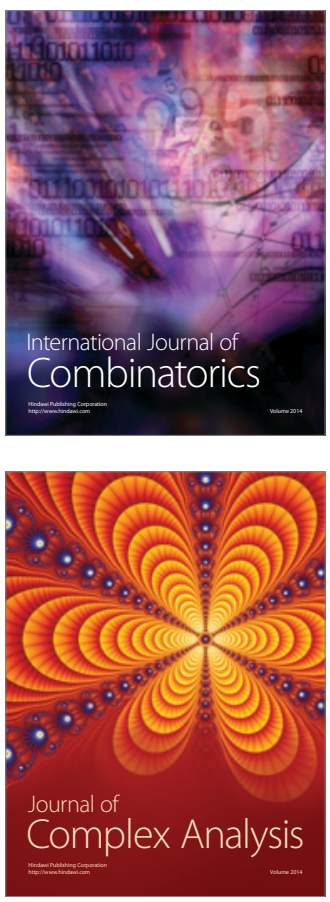

International Journal of

Mathematics and

Mathematical

Sciences
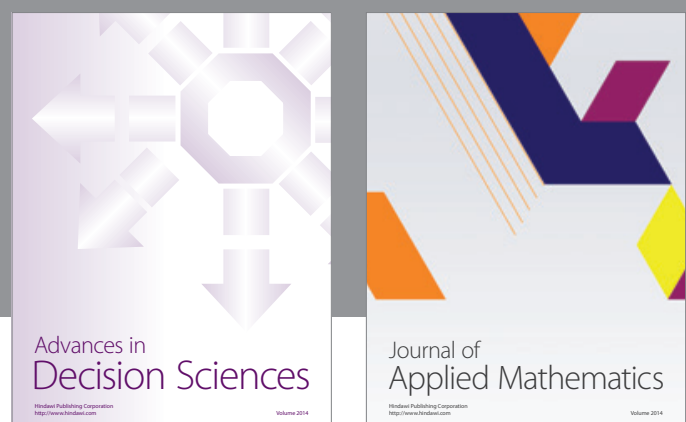

Journal of

Applied Mathematics
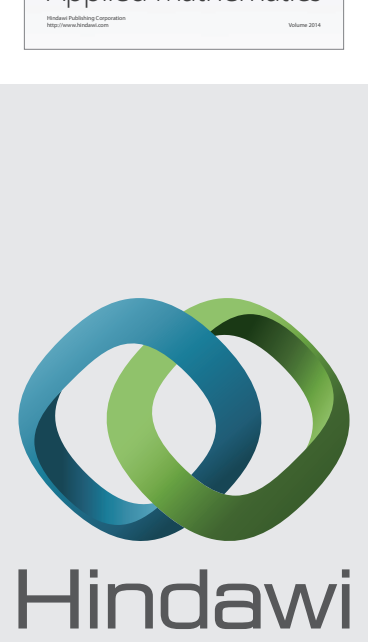

Submit your manuscripts at http://www.hindawi.com
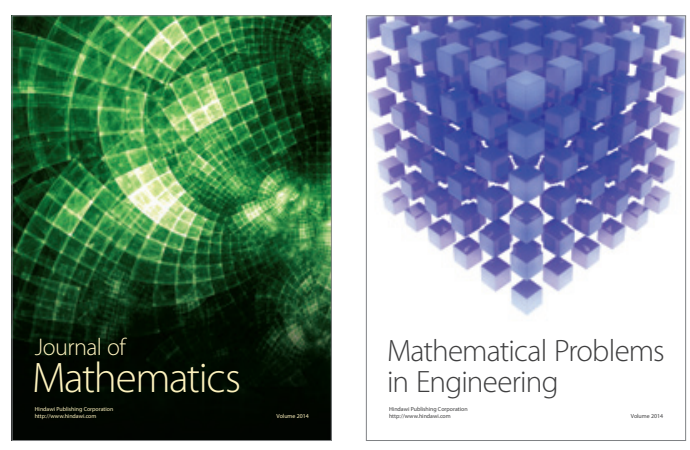

Mathematical Problems in Engineering
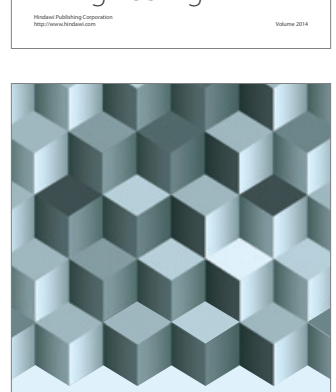

Journal of

Function Spaces
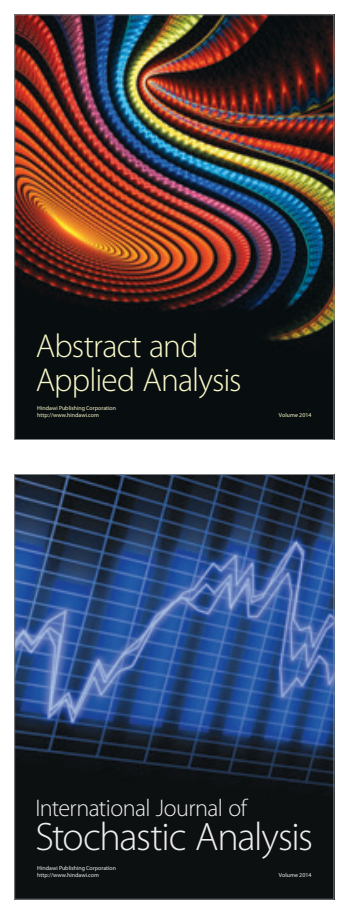

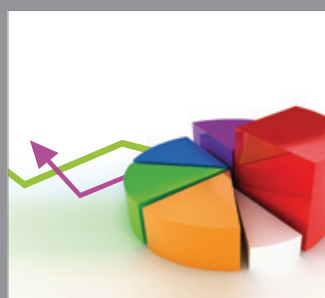

ournal of

Probability and Statistics

Promensencen
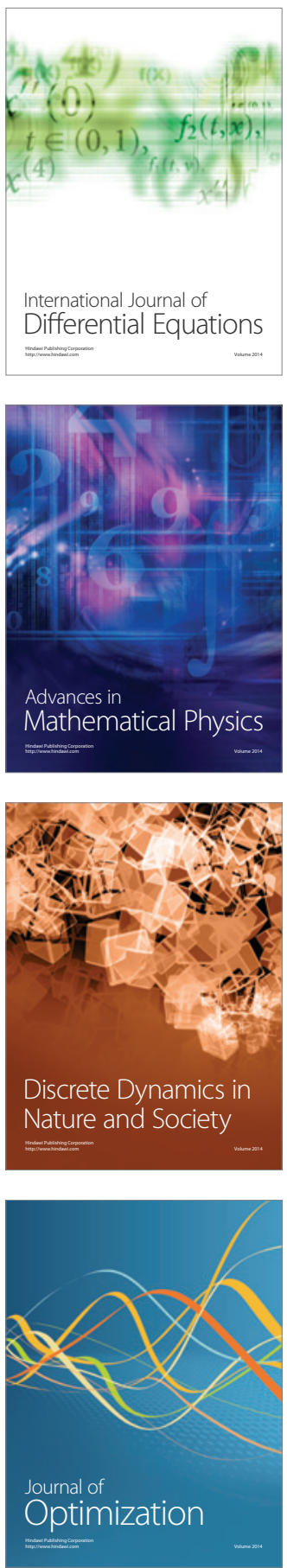